Journal Plus Education, ISSN: 1842-077X, E-ISSN (online) 2068-1151 Vol XIX (2018), No. 1. pp. 238-248

\title{
IN-SERVICE AND PRE-SERVICE TEACHERS' PERCEPTION ON CYBERBULLING
}

\author{
Camelia- Nadia BRAN, PhD \\ „Aurel Vlaicu" University of Arad \\ camelia.bran@uav.ro
}

\begin{abstract}
A fundamental resource in educational programs for preventing and combating cyberbullying are the teachers. Although cyberbullying can happen anywhere in the virtual environment, the formal educational environment is conductive to preventive interventions for all pupils of a class (Wölfer, R., Schultze-Krumbholz, A., Zagorscak, P., Jäkel, A., Göbel, $K$., \& Scheithauer, H. (2014) Based on these prerequisites, we have carried out a study on the in-service and pre-service teachers enrolled at "Aurel Vlaicu" University of Arad, aiming at: identifying how teachers understand concrete manifestations of cyberbullying and recognize a victim-student of cyberbullying, identifying the role of responsible persons in preventing and combating this phenomenon, identifying solutions to combat cyberbullying, identifying the training needs of teachers in the field of prevention and combating cyberbullying. The results shown that the teachers have a non-nuanced representation on the phenomenon of cyberbullying, they stressed the need for training on the topic and considered that parents are the main responsible for children education as regarding safety in virtual environment. The study also highlighted that the phenomenon of cyberbullying is the problem of the whole society, and its solving cannot be left to the sole responsibility of a single institution / factor: "Combating cyberbullying is a current issue that should be debated by each of us. The involvement of everyone is very important. "(V.D).
\end{abstract}

Keywords: cyberbullying; identifying cyberbullying victims; teacher training; intervention programmes;

\section{Theoretical premises}

Cyberbullying is a concept hard to define clearly even by people already working or preparing to work in the educational environment. There are no coherent policies and programs at national level to train in- service and pre-service teachers to recognize, to prevent and fight against cyberbullying among young people. Measures are left to the interference, sometimes unprofessional, of parents, friends, colleagues, etc. 
Intimidated by what is happening to them, young people often avoid asking for help from parents, teachers, or a qualified adult. Consequences are often dramatic: decrease in learning outcomes, isolation, self-mutilation, depression and not isolated, suicide.

A fundamental resource in educational programs for preventing and combating cyberbullying are the in service-teachers and students enrolled in teacher training programmes for all educational levels (preschool, primary, lower secondary and upper secondary). Why them? Because they are close to pupils' age, they use the electronic means of communication and information themselves, they are very active in the virtual environment, and some of them certainly have experiences related to cyberbullying, either as a victim or as an aggressor. Anather important category is represented by the experienced teachers who find themselves powerless in the face of aggression situations in the virtual environment, preferring to (sometimes) ignore the atypical behavioural manifestations of bullied students in the virtual environment and choosing to focus on the contents of the school curriculum.

Starting from this context, we intend to carry out a diagnosis study that aims to identify the perception of current and prospective teachers about the phenomenon of cyberbullying.

The specific objectives of the research were:

- to identify how teachers understand concrete manifestations of cyberbullying

- to identify the extent to which teachers can recognize a victim of cyberbullying

- to identify the extent to which teachers assume the role of responsible persons in preventing and combating this phenomenon

- to identify solutions to combat cyberbullying

- to identify the training needs of teachers in the field of cyberbullying. prevention and intervention.

The hypotheses we wanted to test were:

1. Experienced teachers will more easily recognize the signs of acyberbullying victim compared with pre-service teacher students

2. There is no clear understanding of all aspects of cyberbullying.

3. Teachers assume little responsibility for educating children to deal with cyberbullying

4. There is a real need for teacher training on the phenomenon of cyberbullying The survey was conducted in July 2017 using the questionnaire survey method. 
The questionnaire was applied to a sample of $\mathbf{3 2}$ in-service and preservice teachers, current and former students of "Aurel Vlaicu" University of Arad. The research environment was online, the questionnaire being promoted in virtual groups of former or actual students of the Teacher training programme, who have completed it voluntarily, without sampling, assuming that subjects interested in cyberbullying have autoselected themselves. It turned out to be $90 \%$ of women, $10 \%$ of men.

Regarding the independent variable "age" , one-third $(33.33 \%)$ of respondents were between 36-40 years, $20 \%$ between $41-45$ and $20 \%$ over 45 , as can be seen in figure 1

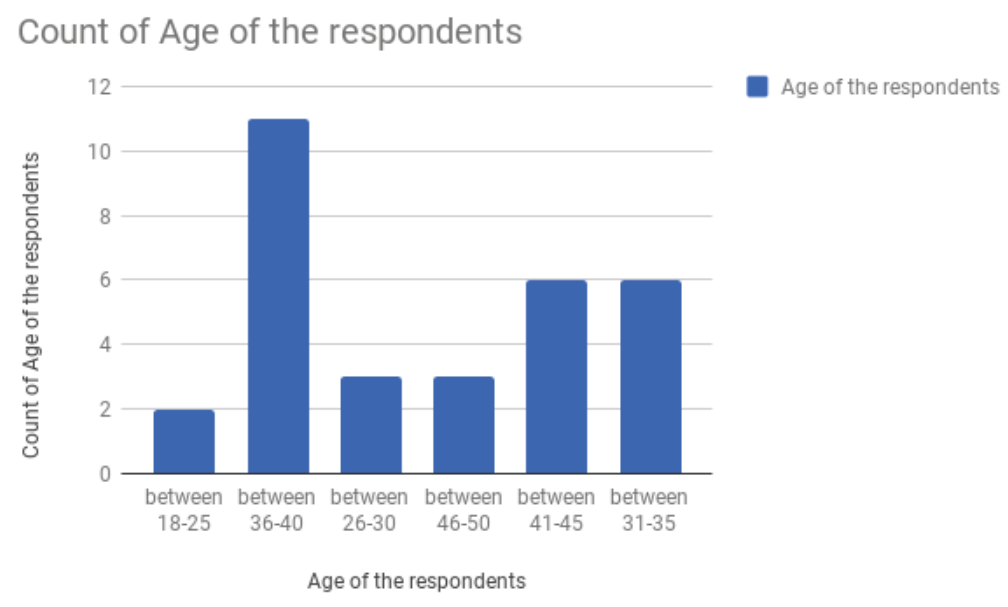

Figure no.1. Respondents distribution after "age” variable

Analyzing the age of the subjects, their work experience and bachelor specialization, we find that $63 \%$ of the subjects have over 10 years of professional experience as teachers, most of them being teachers for primary and preschool education, as shown in the lower graphs 
Count of Bachelor domain:

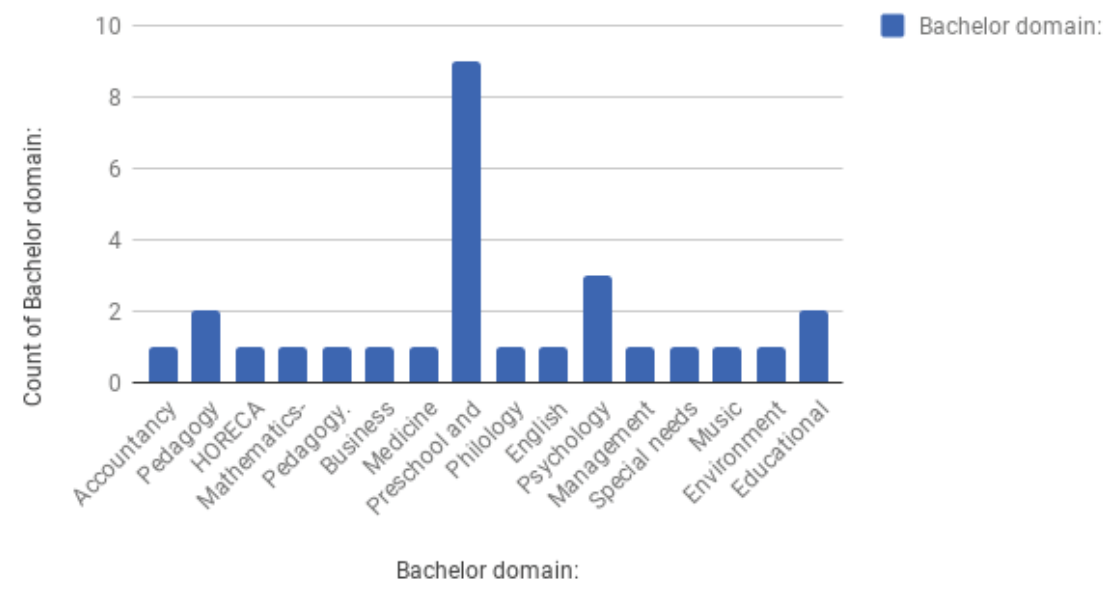

Figure no. 2 Bachelor specialization domain of the respondents

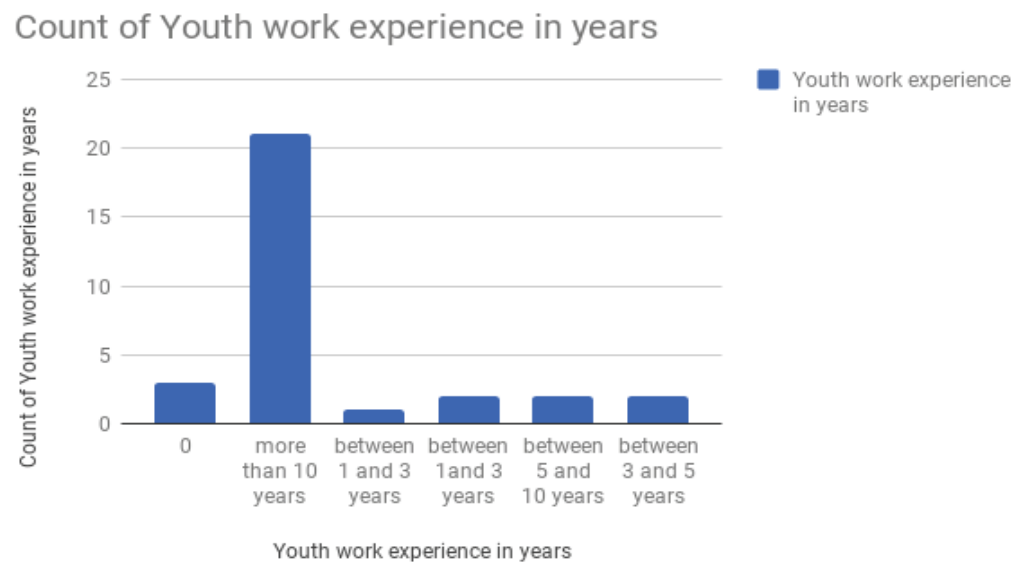

Figure no.3. Youth work experience of the respondents 
Only $20 \%$ of respondents do not have or have little experience working with young people. Research has shown that these experienced respondents are attentive to the children's manifestations, 73\% acknowledging that they have heard of the term cyberbullying. When they explain what cyberbullying mean to them, $50 \%$ of respondents associate it with online harassment and aggression, and other details of the concept such as: spreading false information, verbal violence, mockery, threats, blackmail, intimidation, referral messages or images with offensive content and even terror in order to cause discomfort, defamation. At the item where the subjects of the study were faced with the possibility of choosing the meaning of the concept of bullying based on predefined answers, the elected items indicated the following:

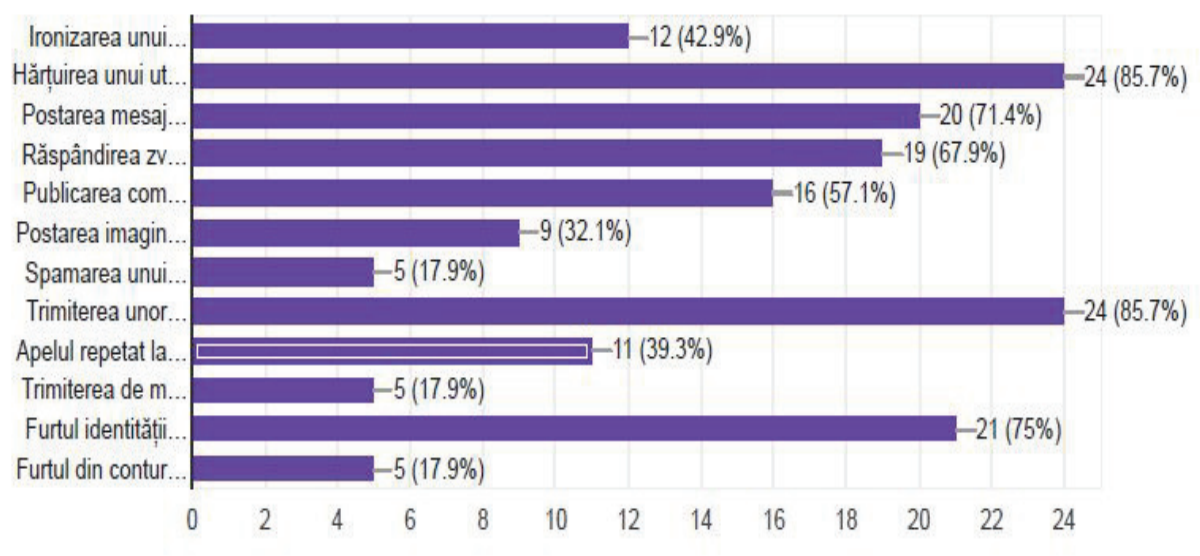

Figure nr.4-Multiple choices option for defining cyberbullying

We find that for $85.7 \%$ of respondents cyberbullying means "harassing a user in an instant messaging session" and "sending out threatening emails", so harassing through written, defamatory language. The theft of a user's virtual identity and posting on his behalf gained $68 \%$ of the vote, with high scores (71.4\%) and also "getting the disturbing Message Post on the facebook page". The fewest choices were received by the variables "spamming of an email account", "trespassing of unsolicited text messages to another user" and "the theft of a user's bank accounts". These manifestations are not as strongly perceived as cyberbullying because both prevention and intervention mechanisms (anti-spam filters, unsubscribe, lock-out, legal sanctions) are available for both spaming and money theft while for cyberbullying, prevention and intervention mechanisms are not so clearly defined. 


\section{Cyberbullying identification}

When it comes to recognize the cyberbullying manifestations among the victims, teachers mainly mention the internalization of the child- victim's beheviour. This "withdrawal" is accompanied by agitation, stress, fear, anxiety, rejection. The child victim of cyberbullying loses interest in school, the school performance decreases and the victims are often disciplinary sanctioned with the decrease of the grade for school behavior due to absences. The victms avoid communication with colleagues and teachers and do not want to talk about similar cases. The students become panicked, have no confidence in the actions they take and most of the time they refuses to talk about the problems they have in the online environment. They are irritable, fearful and panicked because they feel fooled, harassed or threatened. They often manifests a low self-esteem. At the same time, to the question: "How many victims of cyberbullying have you encountered so far? "nearly $60 \%$ of respondents say they do not know a case, so their recognition of cyberbullying victims is rather a hypothetical- theoretical one.

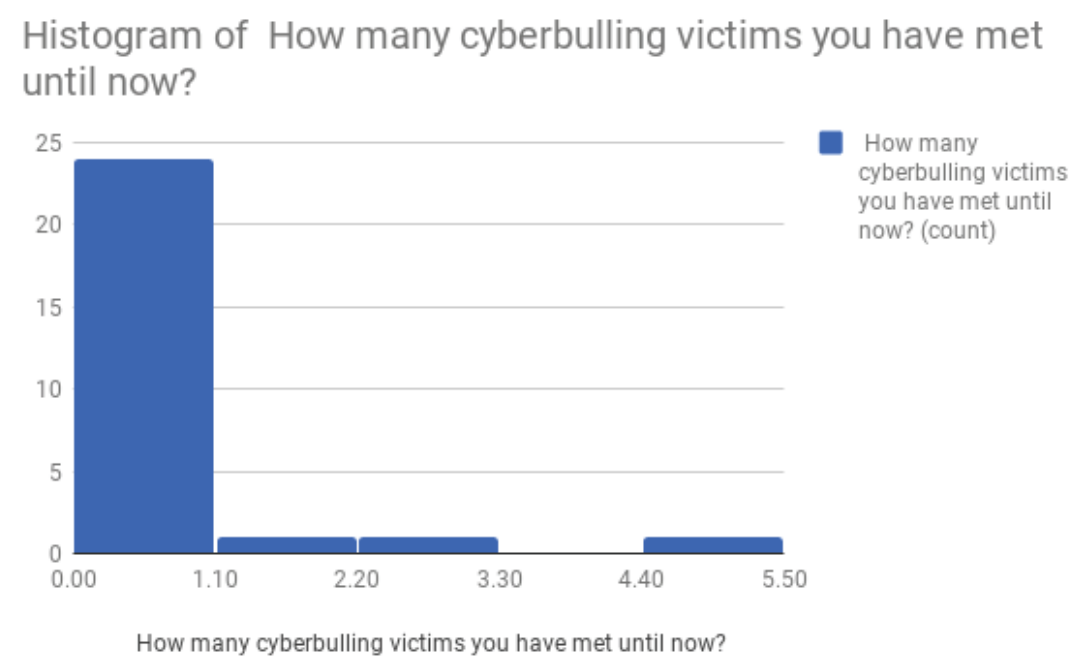

figure no.5. The number of the met cyberbulling victims

\section{Intervention}

Analyzing the subjects' responses to how they intervened when they identified victims of cyberbullying, we find that they refer to direct communication with the child victim, parental notification and counseling and communication with qualified factors such as psychologist, police, Child Protection, Site Administrator, etc. When it comes to cyberbullying intervention and prevention programs, respondents believe that they should 
be made by competent, skilled and experienced people in this area. More respondents have emphasized the importance of counseling by an expert during the councelling hours and not only. The analysis of real cases, the presentation of the situations of victims who have managed to get rid of harassment are other proposals for combating and understanding the phenomenon.

Other interesting intervention suggestions reffered to Consumer Social Networking, Safe Net, Limited Site Access, Limited Program Access, Supplier Deontology.

An effective cyberbullying intervention program should also include young people's personal development activities that give them confidence and encouragement to unmask any inappropriate action from the virtual environment. Respondents believe that informing young people should also address the consequences of aggression in the virtual environment and the importance of reporting harassment when they are witnesses.

Some respondents even propose inclusion of cyberbulling themes in the national curriculum in order to enable students to recognize and respond to harassment and intimidation.

Partnership between school, family, NGOs, public institutions, the media is considered fundamental for the achievement of effective educational programs.

Creation of a support network for students and teachers is another important point of an intervention program highlighted by research subjects. This network would aim to:

- Provide support for teachers to recognize and respond appropriately to online violence.

- Increase the capacity of school counselors to address issues such as harassment, discrimination, violence.

- Creation of a support system for victim students.

Teachers also agree with closer monitoring of children's access to the Internet by accessing and controlling suspicious websites by authorized adults, limited access to Facebook and other online resources, identifying the aggressor, deleting suspicious site blocking comments.

Family counseling sessions to increase parental and child communication would provide preconditions for early family avoidance or intervention in the case of child aggression in the virtual environment. The most synthetic answer given by a respondent refers to an intervention program that leads to:

- Accountability

- Liability

- Information 
- Determination

- Involvement

The question of assuming responsibility for preventing and combating cyberbullying confirms our assumption that teachers are not considered themselves to be the main responsible for safety education in the virtual environment. All subjects were totally in agreement that parents should be educating the child about the phenomenon of cyberbullying. Half of respondents said the psychologist and police have the responsibility to prevent cyberbullying. Responding teachers have somewhat agreed $75 \%$ that teachers are generally responsible for educating on cyberbullying, especially the master teacher who, in their opinion, has this role. Respondents are somewhat agreeing $40 \%$ on the importance of relationships between sameage friends as a means of preventing and combating cyberbullying.

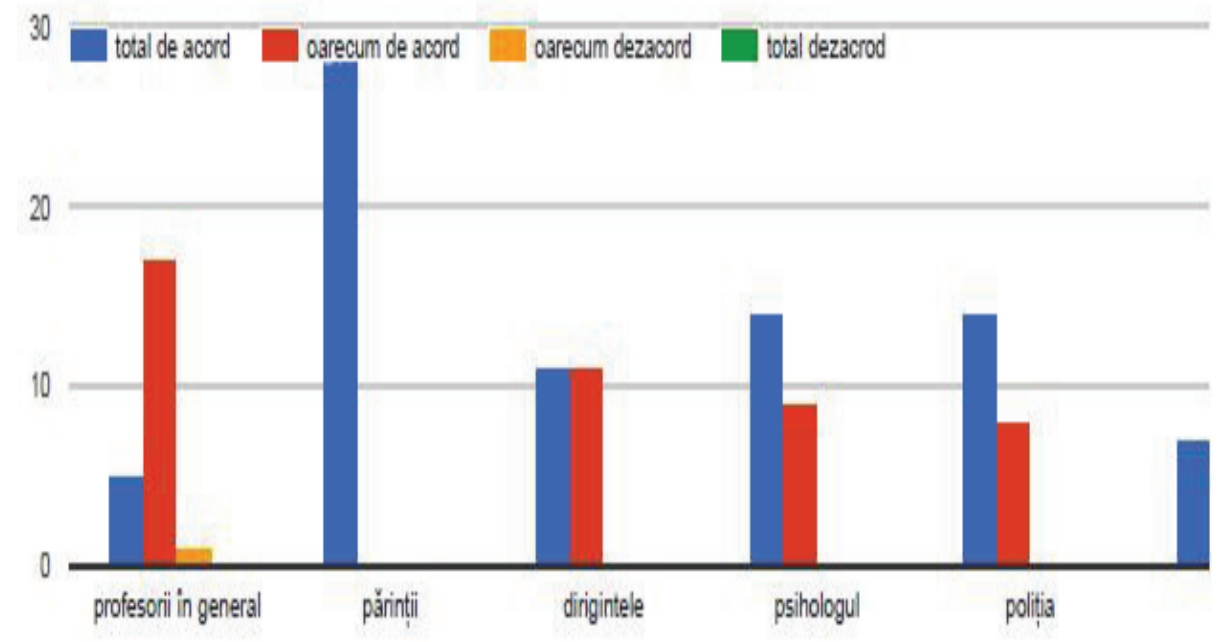

-total dezacrod

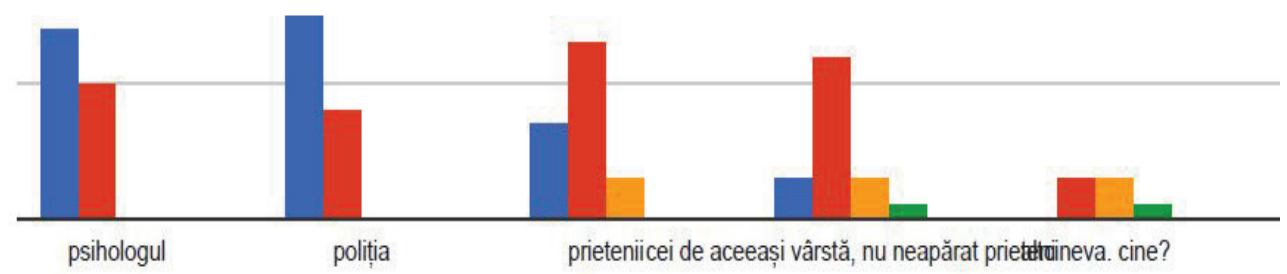

Figure no.6. Agreement and disagreements towards the stakeholders that should action in for cyberbulling prevention and combating 
The explanation that teachers place responsibility on children's education for internet safety to parents may be that teachers feel unprepared to cope with the challenge of cyberbullying among students. This is evidenced by the percentage of $90 \%$ of respondents which consider to a great extent that teachers need training on identifying and combating cyberbullying.

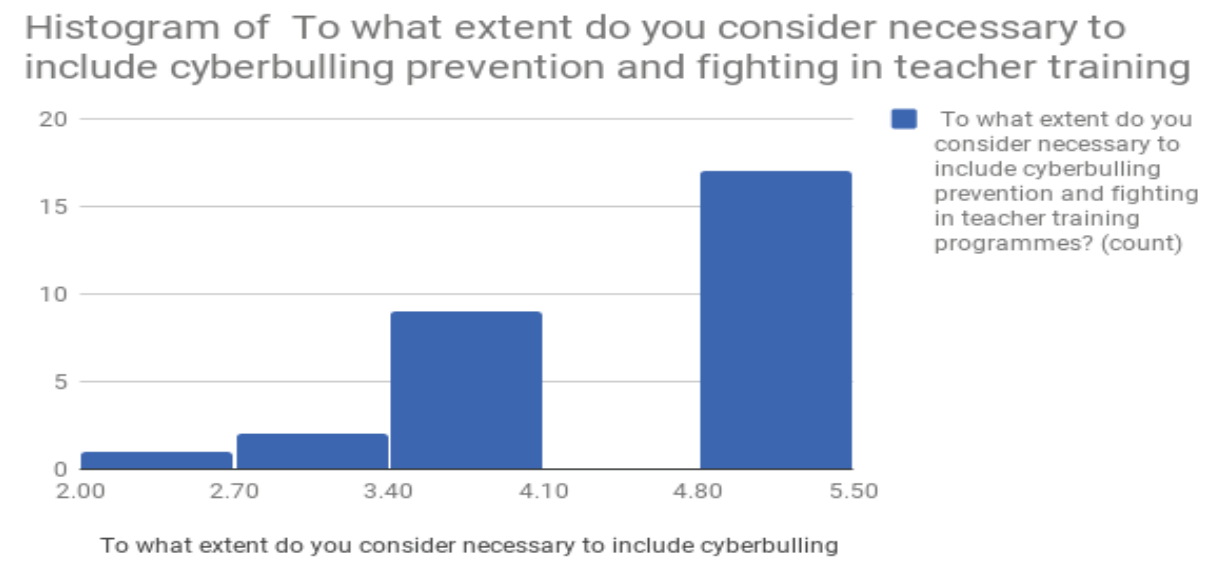

Figure no.7. Extent of training needs of the teachers in the field of cyberbulling (5 means-to a very large extent; 1 means -to a very small extent)

Subjects' preference goes $43 \%$ to open-learning courses, with only a quarter of the subjects favouring face-to-face courses, and $16 \%$ prefer individual

study.

Count of Type of trainings that subject would preffer

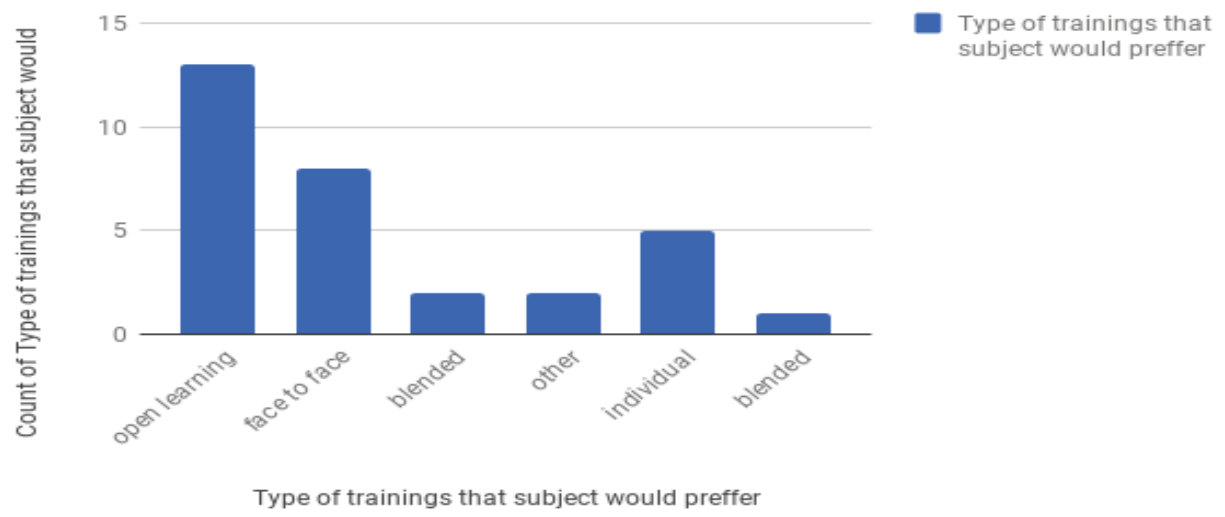

Figure no.8-Types of trainings the subjects would preffer

Why teachers (a category that traditionally prefers face-to-face courses)prefer open-learning courses, is the subject of another research. We 
can see that flexibility, the ability to be followed at own pace, interactivity, gamming, access to other resources, connection to the latest scientific and methodological news are some of the features of open learning courses that make them attractive to active learners on the labor market, who can not easily follow face-to-face courses. Of those who opted for face-to-face courses, 77\% would attend the "Aurel Vlaicu" University's training, second in the order of preferences being the Teaching Staff House.

Although generally open questions do not receive as many responses as closed ones, $45 \%$ of respondents considered it important to point out some aspects of cyberbullying. Their opinions highlight the fact that cyberbullying is a challenge of a constantly changing world, which we, as teachers and parents, need to adapt to. Subjects said that cyberbullying "is a sensitive subject for those who have been or are being put in this situation, and serious treatment by specialists can lead to increased confidence among cyberspace users, not to conform and / or suffer silently. "

One subject of research recognizes that "... it happened to me at a time when I was vulnerable. It was terrible, but I had support from family, close friends, and even from authorities."

In the virtual environment, the boundary between the victim and the aggressor is often unclear. "I think everyone is affected by cyberbulling to a greater or lesser extent and this phenomenon is impossible to stop. An information and knowledge of this phenomenon can avoid the magnitude of situations" .

\section{Conclusions}

Without any claims of representativeness, the study shows that current and future Arad teachers are aware of the problem and extent of cyberbullying among students.

Hypothesis no.1. Experienced teachers are more likely to recognize the signs of a cyberbullying victim compared to future teacher students, is not confirmed because there is no significant difference between the behavioral indicators described by experienced and novice teachers.

Hypothesis number 2. There is no clear knowledge of all facets of cyberbullying, it is confirmed because the definitions developed by the respondents emphasize primarily the aspect of text -based harassment and less other aspects such as spaming, theft of virtual identity, and so on.

Hypothesis number 3. Teachers assume little responsibility for educating children to deal with cyberbullying, it is fully confirmed, because $100 \%$ of respondents strongly agree that parents have a responsibility to identify and prevent cyberbullying. 
Hypothesis 4 There is a real need for teacher training on the phenomenon of cyberbullying, is fully complied with by $90 \%$ of respondents who confirm this need.

The phenomenon of cyberbullying is the problem of the whole society, and its solving can not be left to the sole responsibility of a single institution / factor: "Fighting cyberbullying is a current issue that should be debated by each of us. The involvement of everyone is very important. "(V.D).

Teacher training from the perspective of identifying and intervening in the case of cyberbulling is a need cleamed by teachers themselves and by the growing number of aggressors and victims in the virtual environment. Although cyberbullying can happen anywhere in the virtual environment, the school educational environment is conducive to preventive interventions for all pupils of a class (Wölfer, R., Schultze-Krumbholz, A., Zagorscak, P., Jäkel, A., Göbel, K ., \& Scheithauer, H. (2014) It remains to be seen to what extent traditional institutions providing initial and in-service teacher education will be able to provide relevant, interactive and open programs for the benefit of society as a whole.

\section{References :}

Eden, S., Heiman, T., \& Olenik-Shemesh, D. (2013). Teachers' perceptions, beliefs and concerns about cyberbullying. British Journal of Educational Technology, 44(6), 1036-1052.

O'Moore, M. (2000). Critical issues for teacher training to counter bullying and victimisation in Ireland. Aggressive behavior, 26(1), 99-111.

Li, Q. (2008). Cyberbullying in schools: An examination of preservice teachers' perception. Canadian Journal of Learning and Technology/La revue canadienne de l'apprentissage et de la technologie, 34(2).

Craig, K., Bell, D., \& Leschied, A. (2011). Pre-service teachers' knowledge and attitudes regarding school-based bullying. Canadian Journal of Education, 34(2), 21.

Wölfer, R., Schultze-Krumbholz, A., Zagorscak, P., Jäkel, A., Göbel, K., \& Scheithauer, H. (2014). Prevention 2.0: Targeting cyberbullying@ school. Prevention Science, 15(6), 879-887. 